$11-19-2006$

\title{
Valuable Information and Costly Liquidity: Evidence from Individual Mutual Fund Trades
}

Susan Kerr Christoffersen

Donald B. Keim

University of Pennsylvania

David K. Musto

University of Pennsylvania

Follow this and additional works at: https://repository.upenn.edu/fnce_papers

Part of the Finance and Financial Management Commons

\section{Recommended Citation}

Christoffersen, S., Keim, D. B., \& Musto, D. K. (2006). Valuable Information and Costly Liquidity: Evidence from Individual Mutual Fund Trades. SSRN's eLibrary, http://dx.doi.org/10.2139/ssrn.951501

This paper is posted at ScholarlyCommons. https://repository.upenn.edu/fnce_papers/9

For more information, please contact repository@pobox.upenn.edu. 


\title{
Valuable Information and Costly Liquidity: Evidence from Individual Mutual Fund Trades
}

\author{
Abstract \\ Until recently, all Canadian mutual funds were required to disclose all their individual trades, offering a \\ unique and ideal opportunity to measure and analyze the cost and performance of mutual funds' trades. \\ We find that active management delivers both cheaper trades and better subsequent performance, and \\ that the dissipative effect of flow-driven transactions costs is primarily through forced sales. Fund size \\ associates with both cheaper trades and better subsequent performance, and a series of trades predicts \\ more price movement in the predicted direction, indicating the value to funds of keeping their trading \\ anonymous.
}

\section{Keywords}

mutual funds, trading, trading costs

Disciplines

Finance and Financial Management 


\title{
Valuable Information and Costly Liquidity: Evidence from Individual Mutual Fund Trades
}

\author{
Susan E. K. Christoffersen \\ McGill University \\ Donald B. Keim \\ University of Pennsylvania \\ David K. Musto* \\ University of Pennsylvania
}

November 19, 2006

**Preliminary: Please do not cite without permission**

Until recently, all Canadian mutual funds were required to disclose all their individual trades, offering a unique and ideal opportunity to measure and analyze the cost and performance of mutual funds' trades. We find that active management delivers both cheaper trades and better subsequent performance, and that the dissipative effect of flowdriven transactions costs is primarily through forced sales. Fund size associates with both cheaper trades and better subsequent performance, and a series of trades predicts more price movement in the predicted direction, indicating the value to funds of keeping their trading anonymous.

\footnotetext{
* Corresponding author: David Musto, musto@wharton.upenn.edu, 215-898-4239. The authors are grateful for extensive research assistance from Sameer Bhatnagar, Bobby Boutilier, Feriel Feghoul, Manish Puri, Hao Wang, and Jian Hua. Christoffersen is deeply grateful for financial support from SSHRC and the Canadian Securities Institute Research Foundation.
} 


\section{Introduction}

Consumers throughout the world count on the performance of their mutual funds, and this performance in turn depends on the cost and performance of the funds' trades.

Consequently, there is an extensive empirical literature on this subject. Unfortunately, mutual-fund regulators have generally not required funds to report their trades, so this literature has had to make do with small, self-selected databases of voluntary trade disclosures, or with coarse proxies for trades derived from low-frequency holdings data. However, there is one country which did, for many years, require funds to disclose every trade, and this paper uses these disclosures to address the key questions that only such data can answer.

The exception is Canada. Until June 2005, the Ontario Securities Commission required all funds to disclose not only their periodic holdings but all their interim trades. We compile a database of these trades and link it to data on the funds on the one hand, and the traded stocks on the other. With these three linked databases we calculate the trades' cost and performance, and then determine the important influences on them

One influence of long-standing interest is cash flows in and out of the fund. The attendant trading costs have long been recognized as a potential drag on fund performance (e.g. Edelen, 1999), and a drawback of the open-end structure in general. However, fund managers have some latitude to avoid demanding liquidity where it is in short supply, so the net effect is an open question we can address by relating transaction costs to simultaneous flows.

Similar issues apply to the transactions costs of index funds. Index funds carry significant theoretical and empirical appeal as investment vehicles, but their managers are 
tightly constrained in what to trade and when, whether their trading needs arise from flows or from index changes (e.g. Blume and Edelen, 2004). Their lack of information should in principle bring them better spreads, if they can communicate their innocuous motives, but if it does not, they must demand liquidity regardless of supply. So the net effect on trading costs is an open empirical question we can again take directly to the actual trading costs.

Another influence on a fund's trades of considerable empirical and theoretical interest is the fund's size. In the view of Berk and Green (2004) and Lynch and Musto (2003), a fund's size is an endogenous response to the fund's apparent value-added, and this value addition could manifest as cheaper trade execution, or better subsequent performance. Similarly, in the view of Gervais, Lynch and Musto (2005), fund family size associates with higher managerial value-added, through its effect on the efficiency of managerial retention.

Looking ahead to our results, the key finding among trading costs is the value added by the freedom to provide liquidity. Active managers, despite the presumably higher information content of their trades, trade at lower cost than index managers. And flows are more costly when they necessitate sales, rather than purchases, consistent with the lesser freedom of a manager who must sell rather than buy. We also see lower transactions costs for larger funds, but not for larger fund families.

Tracking the trades ahead to their subsequent returns, we see active managers significantly outperform indexers, from which we can conclude that active managers add value both through patient trading and informed stock-picking. Flows correlate badly with subsequent returns: inflows correspond with flat or negative returns on stocks 
purchased, depending on the sample period, and outflows correspond to flat or positive returns on stocks sold. Both fund size and fund family size correspond with better trade performance, and so does a series of trades. That is, if a fund buys a stock it bought recently, its return going forward is higher, and the reverse holds for sells. This indicates the virtue of managers spreading their trades across brokers, so they don't infer the value of this information, and keep some of it.

After analyzing trading costs and performance separately, we relate the two, asking whether the performance of trades increases with their initial cost. The unconditional answer is that it does for buys but not for sells, but looking closer we see that it does for active funds, whether buying or selling, but index funds have the opposite experience: over the subsequent month, more expensive buys do worse, and more expensive sells do better. So again, the tight constraints of their forced trades hurt their bottom line.

The paper is in seven sections. Section II is a brief review of relevant literature, Section III describes the data, Section IV addresses trading costs, Section V addresses trade performance, Section VI relates costs to performance, and Section VII summarizes and concludes.

\section{Literature Review}

There is extensive interest in trading costs and their effect on performance of mutual funds. Various authors have estimated these costs from CDA/Spectrum holdings data showing quarterly levels, and therefore changes, of portfolio holdings. The test design in many of these studies, dating back to Grinblatt and Titman (1989), is to 
compare the returns of a portfolio assuming holdings were fixed for the quarterly period and compare this to the actual returns of the fund. Kacperczyk, Sialm, and Zheng (2005) find that the difference in the returns of a fund with and without trading has provides explanatory power for future returns and is persistent, suggesting that effective trading ability varies by fund and contributes to overall performance. Wermers (2000) uses holdings changes to infer funds transactions costs, and Bollen and Busse (2005) compare trading costs around the change to decimalization and find that active managers received a significant change in trading costs after decimalization compared to index funds. Frank, Poterba, Shackelford, and Shoven (2004) evaluate the cost of disclosing quarterly holdings by evaluating how profitable it is to mimic portfolio holdings of actively managed funds.

Chalmers, Edelen, and Kadlec (1999) and Edelen, Evans, and Kadlec (2006) add to these findings of trading costs by comparing the holdings information with data on brokerage commissions found in the semi-annual N-SAR filings. They estimate that brokerage commissions add up to $0.30 \%$ of returns and spread costs are $0.47 \%$. To arrive at the estimate of spread costs, the authors match the stocks held by mutual funds with the effective spread of the stock and use this as a proxy for cost.

There is another stream of literature - for example, Keim and Madhavan $(1995,1997)$ - which, like this paper, directly observes individual transactions. Using data from Plexus, these papers analyze how trade execution is related to the size of the trade and other stock-specific factors. The data also enable one to identify who initiates the trade and identify those requiring liquidity. The key contrast between those papers and this one here is that those papers can identify a fund's intentions, so for example identify 
when two 10,000-share trades were a 20,000-share order, but because the funds are anonymous, they cannot link the trading activity to the circumstances of the traders. In this paper we do not observe the fund's trading intentions, only its outcomes, but because these filings are entirely public, we can link the trades to any relevant information about the funds involved.

Some papers (e.g. Chan et al, 2005, Foster et al, 2005, Gallagher et al, 2005) have used the Portfolio Analytics Database, which reports the trades of 34 Australian funds which volunteered some of their trading histories. While this is a small and biased sample, it can potentially contribute to understanding about the determinants of trading costs and performance. Foster et al (2005) show these trades are generally predictive of future performance, and Chan et al (2005) look for an effect of fund size on market impact costs and future performance, but find nothing significant. Gallagher et al (2005) looks at trading around earnings announcements.

\section{Data}

We see all the trades of a Canadian mutual fund in the mandatory "Statement of Portfolio Transactions" it filed with regulators. Until June 2005, mutual funds in Canada were required to report all their individual transacations in annual and interim reports (General Regulation of the Ontario's Securities Act, R. R. O. 1990 Reg 1015, Part IV s. 87-94). In June 2005, the requirement to report individual transactions was eliminated (NI 81-106). Under the previous regulations, mutual funds were required to report all their trades with a maximum 60 day delay on an annual and semi-annual basis. The law did not specify the precise content or form of these reports, and both consequently vary 
somewhat across fund families. Every fund provides the security traded, the number of shares traded, and the amount of the trade which enables us to back out the execution price of the trade (less commissions) by dividing the net dollar amount paid (or received) by the number of shares. The main limitation for our purposes is that only about $15 \%$ of funds report the dates of their transactions. This limitation does not impart any fundspecific bias to the usable sample, because families that don't report dates for one fund don't report them for any.

The public filings by mutual funds are all available from SEDAR (www.sedar.com). We collected all the interim and annual statements of portfolio transactions dated between January 2001 and June 2004, yielding transaction data covering January 2001 through December 2003. These documents are all pdf files which necessitate a labor-intensive transfer to usable form. Thus, we focused on only those filings reporting transaction dates, which were available for 293 mutual and pooled funds of which 210 could be matched to Morningstar. ${ }^{1}$ Of these 210 mutual funds, we observe 336 fund/years of data. In comparison to the full universe of mutual funds in Canada, this matched set represents about $15 \%$ of the total net assets of the entire industry in 2004 . These funds are in four broad categories: Canadian Equity (102 funds), US Equity (47 funds), International (21 funds), and Specialty Funds (40 funds). ${ }^{2}$ This matched sample also contains 20 index funds, as identified by the name of the fund.

\footnotetext{
${ }^{1}$ We have not finished processing the entire database; these are the funds we have so far.

${ }^{2}$ Using Morningstar's category definitions, Canadian funds include Canadian Balanced, Canadian Dividend, Canadian Equity, Canadian Equity Pure, Canadian Tactical Asset Allocation, and Canadian Small Cap. US funds include US Equity, US Small and Mid-Cap, North American and High Yield. International funds include Emerging Markets, Global Balanced and Asset Allocation, Global Equity, and International Equity. Specialty funds include Healthcare, Financial Services, Natural Resources, Science and Technology, RealEstate, Precious Metals, and Miscellaneous.
} 
All trades for each of these funds were collected, but not all trades are in the final sample of the analysis, because we cannot match all trades to trading data for the underlying stocks. Some of the stocks in our data were traded on markets outside Canada and the U.S. so we did not match these trades. If we matched the name of a traded stock with a CUSIP, we identified the trade as a good match only if the execution price derived from the statement of transactions lay between the maximum and minimum price for the day.

All data on the Canadian mutual funds comes from Morningstar and is reported monthly. This data includes management expense ratios, historical returns of the funds, total net assets (which are aggregated across shareclasses for the same fund), sponsor identity, and fund category. In Table I, we provide some summary information about the funds in the sample, averaging across each fund/month. In our sample, the average management expense ratio is $2.21 \%$, the average total net assets for each fund is $\$ 300$ million, ${ }^{3}$ the total net assets of the sponsor is $\$ 18$ billion, and the average monthly rate of return is $0.59 \%$. For comparison to the overall industry, the average Canadian mutual fund has an management expense ratio of $2.48 \%$, a total net asset size of $\$ 158$ million, the sponsor net assets are $\$ 14.86$ billion, and the monthly rate of return was $0.28 \%$. Although a smaller sample of funds, it seems to be representative of the average funds in the industry. In looking at the trades for our matched fund, each fund trades on average 2140 times during the year.

Data on the stocks traded comes from four major sources: Datastream, CRSP, TSX Trade and Quotes Data, and U.S. Trade and Quote Data. The daily information on market returns, stock returns, closing bid and ask prices used to calculate the spread, and

\footnotetext{
${ }^{3}$ All dollar figures in the paper are Canadian dollars.
} 
market capitalization come from Datastream for Canadian stocks and CRSP for U.S.

stocks. The daily average trading volume for the 20 days before the trade, value-weighted average price, and the minimum and maximum price come from the trade and quotes data in each respective market. In the event that a stock is traded in both the U.S. and Canada, we assume the stock traded in Canada and match with the Canadian data. To convert U.S. prices to Canadian dollars, we use the daily exchange rate posted by the Bank of Canada. After some filtering to remove outliers and matching, we are left with 99,988 buy trades (totaling \$29.4 billion) and 67,061 sell trades (totaling \$24.56 billion). ${ }^{4}$ Just under half these sells and buys are trades in Canadian stocks and the rest are trades in U.S. stocks. The break-down of the sample is provided in Panel F of Table I.

As discussed above, our benchmark for estimating the cost of a trade is the departure of the transaction price from VWAP, divided by VWAP. Table II summarizes the trading costs we find in the matched sample. Average trading costs for Canadian stocks are $14 \mathrm{bp}$ for buys and $11 \mathrm{bp}$ for sells while U.S. stocks have similar average costs of $14 \mathrm{bp}$ and $13 \mathrm{bp}$. While these percentage trading are similar across the countries, the average dollar value of the trades is smaller for U. S. stocks; using the total dollar value of trades, these averages translate into an average dollar cost of $\$ 536$ and $\$ 507$ for the average buy and sell trade of a Canadian stock and $\$ 305$ and $\$ 355$ for U.S. stocks. ${ }^{5}$

\footnotetext{
${ }^{4}$ Because the underlying trade and quotes data in both countries has some reporting errors and to remove small priced stocks, we eliminate those trades where the maximum price was more than twice the minimum price in the same day and those stocks with prices below one dollar. There were also some extremely large trades in the data which exceeded 10 times the average trading volume. Because of these outliers, we constrain the trade size to be less than $0.009 \%$ of the market cap of the company and less than twice the trading volume over the preceeding 20 days. These cut-offs are the $99.5 \%$ and $99.9 \%$ cutoffs for each variable respectively.

${ }^{5}$ For example, for the Canadian buy trades, $\$ 536=\frac{\$ 17.65 \mathrm{bil} \times 0.001405}{46131 \text { trades }}$
} 
Our first look at returns subsequent to trading reveals significant short-term predictive power that warrants further exploration. Table II reports that, among Canadian stocks, the average daily excess return over the next week is $4 \mathrm{bp} /$ day for buys, and -6bp/day after sells. Among U.S. stocks, the analogous figures $3 \mathrm{bp} /$ day after buys and $-3 \mathrm{bp} /$ day after sells. All of these returns are strongly statistically significant. Thus, we can conclude that the average trade is informed, at least about the near future.

Lastly, Figures 1 through 5 plot the number of trades and trading costs through time. Figures 1 and 2 show how the total number of trades (before matching, since matching is not relevant for these figures) changes across days of the week for Canadian and U.S. stock trades. We plot the number of trades per day in 2001 to 2003 to control for holidays. Both diagrams show a distinct increase in the number of trades throughout the week where significantly more trades are executed on Fridays than Mondays. These results support the findings in Lakonishok and Maberly (1990) where they find a proxy for instituitonal trading increases over the week. Interestingly, trading costs decrease over the week, as documented in Figures 3 and 4, suggesting that the Lakonishok and Maberly (1990) result may result at least in part from trading costs.. Figure 5 plots the number of trades by month and we see a significant spike in trading in October which would be consistent with trading for tax purposes.

\section{Determinants of Trade Costs}

We begin by estimating a model of the determinants of trade costs. A substantial literature has shown that institutional transactions costs are nontrivial and are influenced by a variety of factors at the level of the trade and at the level of the fund. (See, for 
example, Chan and Lakonishok (1995), Keim and Madhavan (1997), Chiyachantana, Jain, Jiang and Wood (2004).). Trade-level factors include variables that measure the difficulty of the trade (size of the trade, liquidity of the market for the traded stock), the trade venue (electronic, dealer, auction), and the trade direction (buy vs. sell). Fund-level variables are intended to capture the investment style of the institution (which determines the degree of urgency in their demand for immediacy of execution) or the resources available to aid the trading process. We use the following variables to capture these trade cost determinants.

\section{A. Trade- and Stock-Specific Variables}

Research has shown that the price impact of a trade is composed of a variable component related to the size of a trade and a fixed component related to the bid-ask spread of the stock. Our spread variable Spread is the proportional bid-ask spread at the close of the day of the trade. Following previous research, we measure trade size relative to the number of outstanding shares; specifically Trade/MktCap is defined as the ratio of dollar value of shares traded to market capitalization and is stated in percent. We use two variables to capture market liquidity. The first, LogMktCap, is the log of the market capitalization of the traded stock and has been used extensively in previous research. The second variable measures the proportion of the company's outstanding shares that traded on a typical day in the period leading up to the trade. Specifically, Vol/Shrout is defined as the average daily trade volume for the traded stock, measured over the 20 trading days prior to the trade, divided by the stock's total shares outstanding. CanUS is an indicator variable that equals one if a Canadian stock, zero if a U.S. stock. Previous research has 
shown that trade costs vary across different market venues; this variable is intended to detect cost differences between the Toronto Stock Exchange (an electronic limit order book market) and US exchanges (future drafts will also distinguish between trades executed on Nasdaq (dealer) and NYSE (specialist/auction)). Finally, and unlike some recent studies using proprietary data that enable researchers to re-package individual trades together into a larger order (or block) corresponding to the trader's total desired trade size, the individual trades in our data cannot be identified as part of some larger order quantity. In an effort to determine whether an individual trade is part of a larger trade program, we create an indicator variable ClosePastTrade which equals one if the fund traded the stock at any time during the week prior to the trade, zero otherwise. Finally, to capture differences in the combined effects of these variables in buying or selling situations, we estimate the regressions separately for buys and for sells.

\section{B. Fund-Specific variables}

In addition to trade- and stock-specific variables we include several fund-level variables. Because we know the identity of the funds in our sample we can clearly identify their investment style. Chan and Lakonishok (1995), Keim and Madhavan (1997) and others have shown that funds' investment styles influence their demands for immediacy and thus their resulting trade costs. The trades of active fund managers are motivated by information, but the degree of immediacy demanded depends on the speed at which the value of the information decays. Thus, momentum managers who are chasing short-term

price trends display extreme demand for immediacy, while value-oriented managers (e.g., Warren Buffett), relying on information that is longer-lived, can be more patient in 
getting into a position and thereby display less demand for immediacy. These differing demands for immediacy will be reflected in differences in trade costs. The trades associated with portfolios that are tied to an underlying index are not motivated by information but, nevertheless, display a relatively high demand for immediacy as they attempt to minimize the deviation of their portfolio weights from the weights in the underlying index. We currently distinguish between index funds and non-index funds with the variable Active which equals one if the fund is not an index fund, zero otherwise. (Future drafts will employ finer distinctions between the investment styles of the nonindex funds in our sample.)

Previous research finds that mutual fund costs are inversely related to fund size, suggesting a fixed component to costs and corresponding economies of scale (Colins and Mack (1997), Tufano and Sevick (1997), Chalmers, Edelen and Kadlec (1999), and Evans, Edelen, and Kadlec (2006)). Chalmers, Edelen and Kadlec(1999) find that the inverse relation is weaker when estimated with fund trade costs suggesting such economies of scale are less important for the more variable nature of costs associated with trading. But their estimated trade costs are approximated by trading implied by changes in quarterly holdings and are a coarse measure of costs. Our data on actual trades permit a cleaner estimation of the relation between trade costs and fund size. Our variable for fund size is $\log T N A$, the $\log$ of the total net assets of the fund measured at the end of the month of the trade. We also include a variable to capture any further economies associated with a larger parent or sponsor organization - logTNAsponsor is the log of the total net assets of the fund sponsor measured at the end of the month of the trade. 
Finally, we include a variable related to the net flow of investment in the fund.

For a trade executed in month $t$, we measure Flow as $T N A_{t}-T N A_{t-1}\left(1+R_{t}\right)$ where $T N A_{t}$ is the total net assets of the fund at the end of month $t$ and $R_{t}$ is the net rate of return for the fund during month $t$. We then distinguish between positive and negative net flows with the variable FlowPos defined to be one if Flow is positive, zero otherwise.

\section{Results}

We model trade costs as a linear function of the variables described above and estimate the model separately for buys and sells using ordinary least squares for the January 2001 - June 2004 period. We report the estimated coefficients and t-values based on heteroskedasticity-consistent standard errors in Table III. The adjusted $R^{2}$ values are low, but most of the estimated coefficients are significant and consistent with expectations based on the discussion above. As in previous research, the coefficient on Trade/MktCap is positive and significant for both buys and sells indicating larger trades are more expensive. The two variables measuring the liquidity of the market for the traded stock, LogMktCap and Vol/Shrout, are both negative and significant for buys, although only LogMktCap is significant for sells. Thus, stocks trading in less liquid markets are more expensive to trade. The coefficient on spread is positive but insignificant for the trades in our data. The insignificance could reflect the noisiness of closing quotes (future drafts will use value-weighted effective spreads, now being calculated). The coefficient on ClosePastTrade is negative and significant for both buys and sells, indicating that a gradual campaign to put on or take off a position associates with lower trading costs. 
The effect of flows on trading costs reflects two opposing forces. On the one hand, flows create some urgency to trade: inflows require buys and outflows require sells. The urgency is likely higher in the outflow case, since the downside from not having cash to fund outflows is likely greater than the downside from not getting inflows to work quickly. On the other hand, flows allow funds to optimize across possible trades, providing rather than demanding liquidity if possible. Again, this is likely more beneficial for inflows than outflows, because a manager picking a stock to buy is less constrained than a manager picking a stock to sell, as the latter can pick only from his current holdings, and some of these holdings may be costly to sell from a tax perspective. What we find is the FlowPos is insignificant for buys but significantly positive for sells, and in particular, in the last column we see that negative flows increase the cost of sells more than positive flows increase the cost of buys, bearing out the view that inflows create more urgency and allow less choice across stocks, both of which reduce the manager's ability to provide liquidity.

The coefficient on Active is negative and significant for buys but insignificant for sells, suggesting that, other things equal, non-indexers have lower costs than indexers. This is not inconsistent with earlier results (e.g., Keim and Madhavan (1997)) and can be attributed to several factors. As described above, indexers have a high demand for immediacy in their efforts to match the underlying index. On the other hand, active value-oriented managers can trade patiently, often supplying liquidity and, thereby, enjoy relatively low trade costs. And other active strategies, other than momentum strategies, have incentives to camouflage their intentions (and, thus, the information motivating their trades) by breaking orders into smaller transactions with lower individual price impacts. 
It is plausible that the mixture of active managers in our non-index category contains a sufficiently large percentage of these kinds of active managers so that their average costs, controlling for the other variables in the model, are lower than for indexers.

Consistent with Chalmers, Edelen and Kadlec (1999) we find that the coefficient on $\log T N A$ is negative and significant for both buys and sells, indicating there are economies of scale in trading for the funds in our sample. However, the coefficient on

logTNAsponsor is positive and marginally significant for both buys and sells, suggesting that such economies do not extend to the larger umbrella of the sponsoring organization. Finally, the coefficient on CanUS is negative and significant for both buys and sells, which could indicate a trading-cost advantage for Canadian managers trading Canadian stocks.

\section{Performance of Trades}

\section{A. Motivation for the tests}

We are interested in the relation between the performance of the trades in our sample, as measured by post-trade market-adjusted returns on the traded stocks, and variables related to characteristics of the trade, the stock being traded, and the fund making the trade. To measure trade performance, we compute for each trade in our sample the return for the traded stock in excess of the market return (the return on the TSX300 for Canadian shares, the return on the S\&P500 for U.S. shares) for three posttrade intervals - one week (5 trade days) following the trade, one month (21 trade days) following the trade, and three months (63 trade days) following the trade. We regress these post-trade returns on trade-specific (Trade/MktCap, ClosePastTrade), stock- 
specific (CanUS), and fund-specific variables (Active, FlowPos, LogTNA, LogTNAsponsor) defined in section IV.

The trade-specific variables are intended to capture characteristics of the trade related to informational value - Trade/MktCap and ClosePastTrade. Past research suggests that trade size is positively related to the information content of the trade. The second variable indicates that the individual trade was part of a larger desired order quantity by the fund for the stock and, therefore, conveys a possibly greater signal of informational value than suggested by its individual trade size.

The stock-specific variable (CanUS) is included to examine whether the geographic location of the company of the traded stock exhibits a relationship with posttrade returns. The geographic location of a company may be related to the quality of the information an investor has about the company's stock value. Specifically, the investor may be more familiar with, and have better information about, stocks domiciled close to the investor's home (e.g., Moskowitz and Coval (1999), Huberman (2001)). An implication is that Canadian fund managers may have a comparative advantage when investing in Canadian stocks.

The fund-specific variables are included to capture characteristics of the fund related to the probability of their being informed (Active), the extent to which flows into or out of the fund impact the relative proportion of informed versus liquidity-motivated trades (FlowPos), and the degree to which the level of resources available to the fund manager provides an informational advantage (LogTNA, LogTNAsponsor). We expect the trades of index managers to be liquidity-motivated and, therefore, unrelated to posttrade returns. In contrast, the trades of non-index funds, if informed, will be related to 
post-trade returns. As Alexander, Cici and Gibson (2006) observe, positive flows oblige the manager to buy something, and this reduces the likely information content of the purchase, whereas positive flows reduce the pressure to sell something, thereby increasing the likely information content of any sells that do occur.. Finally, funds and sponsoring organizations with more assets under management will have access to more resources and greater ability to identify valuable information. Thus, we expect that larger funds will produce trades with better subsequent performance.

In addition, we include two variables to control for observed market-wide patterns in returns related to size (Banz (1981)) and price momentum (Jegadeesh and Titman (1993)) that we don't want to attribute to manager skill. These variables are the log of the market capitalization of the traded stock (LogMktCap), and the market-adjusted return for the traded stock for the month (21 trade days) prior to the trade (XRetLag1Mo), adjusted for the TSX300 and S\&P500, as described above.

\section{B. Results}

The results from our trade performance regressions are in Table IV. We estimate regressions separately for buy and sell trades; and for both buys and sells we estimate three separate regressions for our three post-trade return intervals. The controls for the size (LogMktCap) and momentum (XRetLag1Mo) effects are significant and in the expected direction. As expected, momentum is more pronounced the longer is the posttrade return interval, but it is interesting that the momentum effect is more pronounced in the excess returns following buys than for sells. 
Turning to the trade- and stock-specific variables, the coefficient on Trade/MktCap is negative and significant for buy trades, but only for one-week posttrade returns, and positive and significant for sells for all three post-trade intervals. This finding that larger trades underperform smaller trades in the short term, coupled with their being more expensive (from the previous section), suggests a demand for immediacy. The greater (absolute) post-trade returns following larger trades reflects a rebound from the larger temporary (i.e., liquidity) price concessions required for those trades, or possibly that informed trades are optimally broken up into smaller-sized pieces for execution. The coefficient on ClosePastTrade is positive and significant for buys and negative and significant for sells for one-week market-adjusted returns, indicating that individual trades that are part of a larger trade program signal greater informational value than would be suggested by their individual trade sizes. Of course it is possible that the trade, if part of a larger order, may be followed by subsequent trades in the following week, so that the higher one-week post-trade excess return we observe simply reflects liquidity effects related to the fund's continued presence in the market. To control for this, we construct a variation on ClosePastTrade, ClosePastTrade2, defined to be equal to one if the fund traded the stock at any time during the week prior to the trade but not in the subsequent week, and zero otherwise. The coefficient on ClosePastTrade2 is positive and significant, and approximately twice the value of the coefficient on ClosePastTrade for buys for one-week market-adjusted returns, so the positive subsequent return is not driven by future purchases by the same fund. On the other hand, for buys ClosePastTrade2 does not come in at all. This is consistent with the future sells causing 
the negative return, but the causality could be the other direction; subsequent poor returns could encourage managers to sell again.

Finally, the coefficients on CanUS are negative and generally significant for both buys and sells across all post-trade return horizons, indicating that Canadian stock buys underperform U.S. stock buys for our sample of Canadian funds, whereas Canadian stock sells outperformed U.S. stock sells. Although the sell results speak to the Canadian funds' comparative advantage when trading Canadian stocks, the buy results are inconsistent with this. One possible reason for this could be an important factor in returns (e.g., value effect, which was strong in our sample period) for which we have not controlled (e.g., it is possible that the Canadian stocks bought and sold in our sample were more growth-oriented than the U.S. stocks).

The results for our fund-level variables are consistent with our predictions. The coefficient on Active is positive and significant for buys and negative and significant for sells, showing that the trades of non-indexers outperform the trades of indexers in our sample. As expected, this differential performance decays as the post-trade interval increases. The coefficients on logTNA and logTNAsponsor are positive and significant for buys and negative and significant for sells. This finding is consistent with our prediction that funds and sponsoring organizations with more assets under management have access to more resources and greater ability to identify valuable information and, therefore, will produce trades with better subsequent performance. We find that the magnitude and significance level of this effect declines with longer post-trade horizons. Finally, the coefficient on FlowPos is negative and significant for both buys and sells at post-trade intervals of one and three months indicating that, consistent with Cici, 
Alexander and Gibson (2006), cash inflows do indeed increase the performance of sells and decrease the performance of buys.

\section{Relation between Trade Costs and Performance}

In this section we ask whether there is a relation between the cost of a trade and its subsequent performance by modifying the trade performance model estimated in section $\mathrm{V}$ to include an estimate of the predicted cost of the trade. We compute the predicted trade cost ExpTradeCost using the parameters from the model of trade costs in section IV, estimated separately for buys and for sells, in conjunction with the trade- , stock- and fund-specific characteristics associated with each trade. We estimate the model using market-adjusted returns for the one-week and one-month post-trade intervals. The results are reported in Table V, separately for buys and sells.

The first column in each panel of Table $\mathrm{V}$ shows the results with the extended model that includes the predicted cost of the trade. The coefficient on ExpTradeCost is positive and significant with the exception of sells at the shorter post-trade horizon.

Thus, higher trade costs are related to higher performance, suggesting an information as well as a liquidity component in predicted trade costs. This conjecture is confirmed in the second column where we add to the model an interaction term defined as (ExpTradeCost * Active) where active is defined as above. If trades of active funds are more informed than trades of indexers so that costs include a permanent price impact related to that information, then the coefficient on the interaction term will be positive and significant for the buys and negative and significant for the sells. We find this to be the case except for the short-term performance of the sells. We also find for the buy 
regressions that the coefficient on the non-interacted ExpTradeCost is now insignificant for one-week returns and significantly negative for one month returns, confirming that the liquidity motivated trades of the indexers in our sample are not related to positive performance. The results for the sell regressions suggest a similar interpretation.

We find that adding ExpTradeCost and the interaction variable to the model does not, in general, change the estimated coefficients for the other variables or their significance levels. Two exceptions are Active, which is now insignificant due to the presence of the interaction term which incorporates this effect, and CanUS which is now insignificant for the buy regressions, and is negative and significant only for the sell regressions for the one-week post-trade return.

We also experimented with several additional specifications of the model with information-related interaction terms related to trade characteristics (CloseTradePrice) and fund characteristics (TNA, FlowPos). The results for these interaction variables were somewhat mixed and mostly insignificant. One exception is the interaction with TNA, intended to capture the greater informational advantage of larger funds, which is positive and significant for buys and negative and significant for sells, consistent with higher costs for these firms containing a significant information component.

\section{Conclusion}

Canadian regulators provided a major and singular opportunity to discover the economics of mutual-fund trading when they required funds to disclose all their trades. This paper begins the discovery by taking the natural first questions to this data, asking where the cost and performance of trades come from. 
In the costs of trades we see clearly the downsides of two popular features of the mutual-fund industry: indexing and the open-end structure. Indexing presumably eliminates much wasteful trading, but it also handcuffs traders, and we see the resulting poor execution. The efficiencies of the open-end structure are also well-known but so is the potential for expensive trading frictions. We see those frictions, but we also see that forced buys are handled more cheaply than forced sells, in accordance with the looser constraints managers face. Large funds trade more cheaply, maybe because size gives some advantage, or maybe because funds that trade well attract investors.

In the trades' future performance we again see indexers suffering in comparison to active traders, the trades associated with net flows doing poorly, and larger funds performing better. We also see the value of anonymity to fund managers: the return after an active manager's trade goes further in his direction if it follows another trade, showing the importance of keeping one's trading pattern to oneself.

This is a young project, and we are in the midst of expanding it on all dimensions. But it is already apparent that the Canadian mutual-fund industry, over the years of this disclosure policy, is the ideal resource for the key questions about mutual-fund trading. 


\section{References:}

Alexander, Gordon J., Gjergji Cici, and Scott Gibson, 2006, Does motivation matter when assessing trade performance? An analysis of mutual funds, Forthcoming in the Review of Financial Studies.

Baker, Malcolm, Lubomir Litov, Jessica A. Wachter, and Jeffrey Wurgler, 2004, Can mutual fund managers pick stocks? Evidence from their trades prior to earnings announcements, SSRN working paper.

Banz, Rolf, 1981, The relationship between return and market value of common stocks, Journal of Financial Economics 9, 3-18.

Berk, Jonathan, and Richard C. Green, 2004, Mutual fund flows and performance in rational markets, Journal of Political Economy 112, 1269-1295.

Bollen, Nicholas P. B. and Jeffrey A. Busse, 2005, Tick Size and Institutional Trading Costs: Evidence from Mutual Funds, Forthcoming in the Journal of Financial and Quantitative Analysis.

Chalmers, John M. R., Roger M. Edelen, and Gregory B. Kadlec, 1999, Transaction-cost expenditures and the relative performance of mutual funds, Working Paper \#00-02, Wharton Financial Institutions Center.

Chan, Howard, Robert W. Faff, David R. Gallagher, and Adrian Looi, 2005, Fund size, fund flow, transaction costs, and performance: Size matters, Working Paper, University of New South Wales.

Chan, Louis K. C., and Josef Lakonishok, 1995, The behavior of stock prices around institutional trades, Journal of Finance 50, 1147-1174.

Chen, Hsiu-Lang, Narasimhan Jegadeesh, and Russ Wermers, 2000, The value of active mutual fund management: An examination of the stockholdings and trades of fund managers, Journal of Financial and Quantitative Analysis, September, 343-368.

Chen, Joseph, Harrison Hong, Ming Huang, and Jeffrey D. Kubik, 2004, Does fund size erode mutual fund performance? The role of liquidity and organization, American Economic Review, 94(5), 1276-1302.

Chiyachantana, Chiraphol N., Panjak K. Jain, Christine Jiang, Robert A. Wood, 2004, International evidence on institutional trading behavior and price impact, Journal of Finance 59, 869-898.

Collins, Sean and Phillip Mack, 1997, The optimal amount of assets under management in the mutual fund industry, Financial Analysts Journal, 53(5), September/October. 
Coval, Josh, and Toby Moskowitz, 1999, Home bias at home: Local equity preference in domestic portfolios, Journal of Finance 54, 1-39.

Edelen, Roger M., 1999, Investor flows and the assessed performance of open-end mutual funds, Journal of Financial Economics 53, 439-466.

Edelen, Roger M., Richard Evans, and Gregory B. Kadlec, 2006, Volume-weighted trading costs and mutual fund performance, Working Paper, Boston College.

Foster, Douglas F., David R. Gallagher, and Adrian Looi, 2006, Institutional Trading and Share Returns, Working Paper, University of New South Wales.

Frank, Mary Margaret, James M. Poterba, Douglas A. Shackelford, and John B. Shoven, 2004, Copycat funds: Information disclosure regulation and the returns to active mangaement in the mutual fund industry, Journal of Law and Economics, 47, 515-541.

Gallagher, David R., 2003, Investment manager characteristics, strategy, top management changes and fund performance, Accounting and Finance 43, 283-309.

Gallagher, David R., Adrian Looi, and Matt Pinnuck, 2005, Institutional trading around earnings announcements, Working Paper, The University of New South Wales.

Gervais, Simon, Anthony Lynch and David Musto, 2005, Fund Families as Delegated Monitors of Money Managers, Review of Financial Studies 18, 1139-1169.

Grinblatt, Mark, and Sheridan Titman, 1989, Mutual fund performance: an analysis of quarterly holdings, Journal of Business 62, 393-416.

Huberman, Gur, 2001, Familiarity breeds investment, Review of Financial Studies 14, 659680 .

Jegadeesh, N., and Sheridan Titman, 1993, Returns to buying winners and selling losers: Implications for stock market efficiency, Journal of Finance 48, 65-91.

Kacperczyk, Marcin, Clemens Sialm, and Lu Zheng, 2005, Unobserved Actions of Mutual Funds" NBER Working Paper \#11766.

Karceski, Jason, Miles Livingston, and Edward S. O’Neal, 2004, Mutual Fund Brokerage Commissions, Working Paper, University of Florida/Wake Forest University.

Keim, Donald B., Ananth Madhavan, 1995, Empirical evidence on the behavior of institutional traders, Journal of Financial Economics 37, 371-399.

Keim, Donald B., Ananth Madhavan, 1997, Transaction costs and investment style: An interexchange analysis of institutional equity trades, Journal of Financial Economics 46, 265-292. 
Lynch, Anthony, and David Musto, 2003, How investors interpret past fund returns, Journal of Finance 58, 2033-2058.

Sevick, Mathew and Peter Tufano, 1997, Board structure and fee-setting in the U.S. mutual fund industry, Journal of Financial Economics, 46, 321-356.

Wermers, Russ, 2000, Mutual fund performance: An empirical decomposition into stockpicking talent, style, transactions costs and expenses, Journal of Finance 55, 1655-1695. 


\section{Trades of Canadian stocks per day}

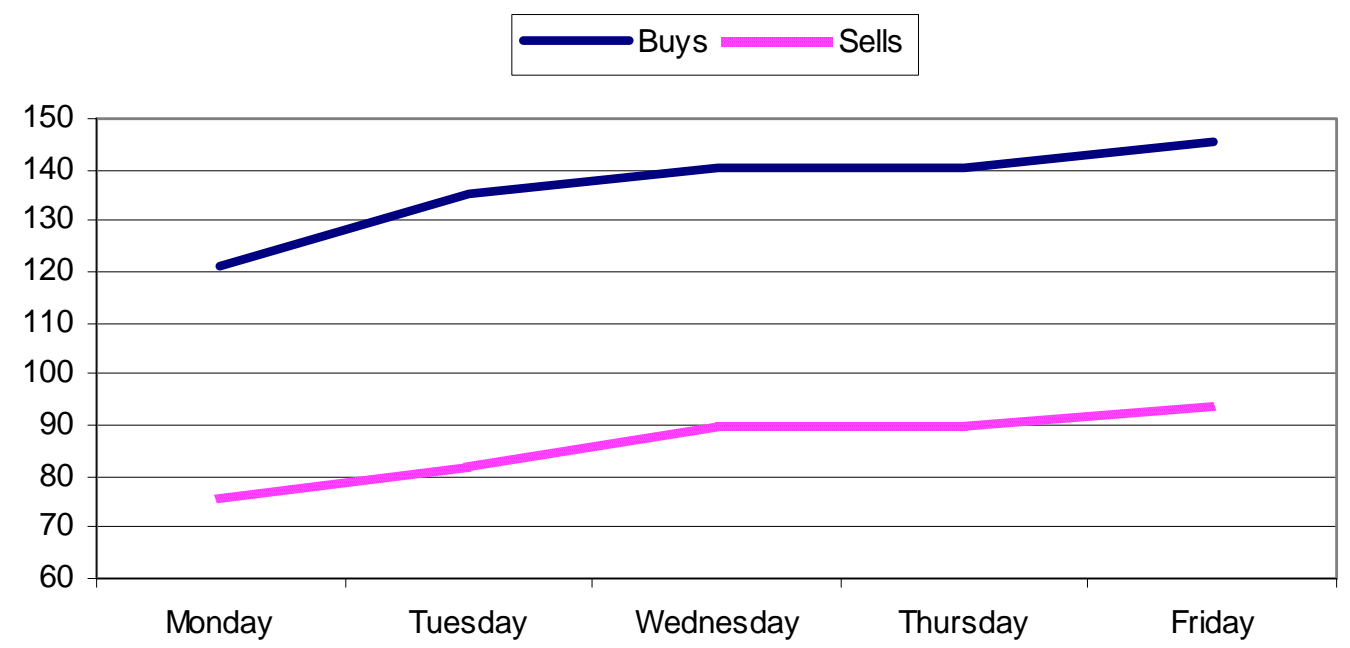

Figure 1. This plots the average number of trades in Canadian stocks per trading day in 2001 to 2003. This represents all trades of 293 Canadian mutual funds.

\section{Trades of US Stocks per day}

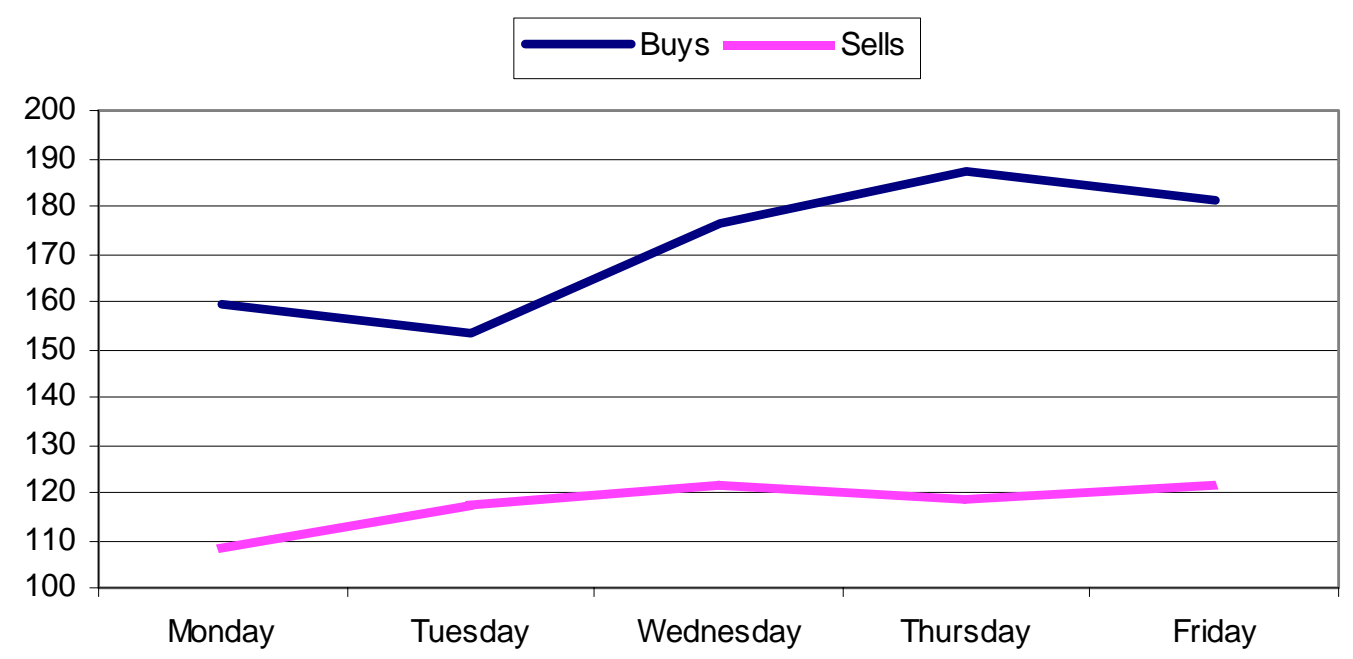

Figure 2. This plots the average number of trades in U.S. stocks per trading day in 2001 to 2003. This represents all trades of 293 Canadian mutual funds. 


\section{Average Trading Costs (\%) for Canadian Stocks}

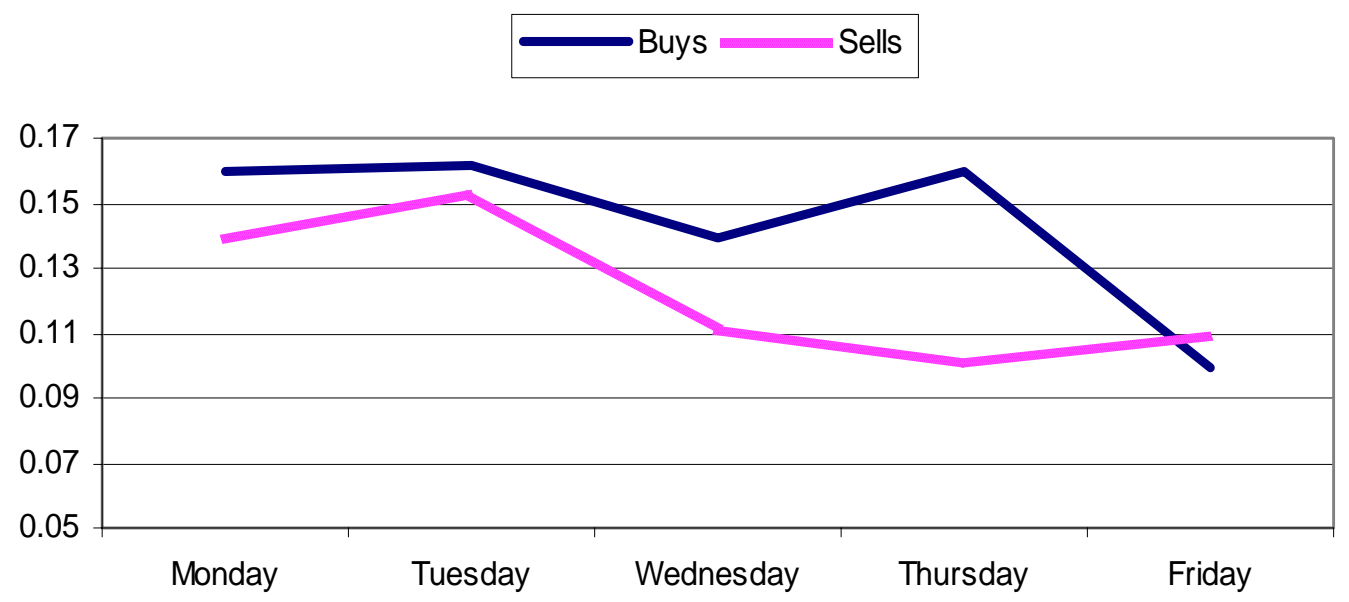

Figure 3. This plots average trading costs ( in percent) of Canadian stocks between 2001-2003. This represents average costs of 105,755 trades for 293 mutual funds where trades were matched with underlying price information. Trading costs for buys are estimated as the difference of execution price from the value-weighted average price, VWAP, of all trades during the day divided by VWAP. Trading costs for sales are estimated estimated as the difference of value-weighted average price and execution divided by VWAP.

\section{Average trading costs (\%) by Day of Week}

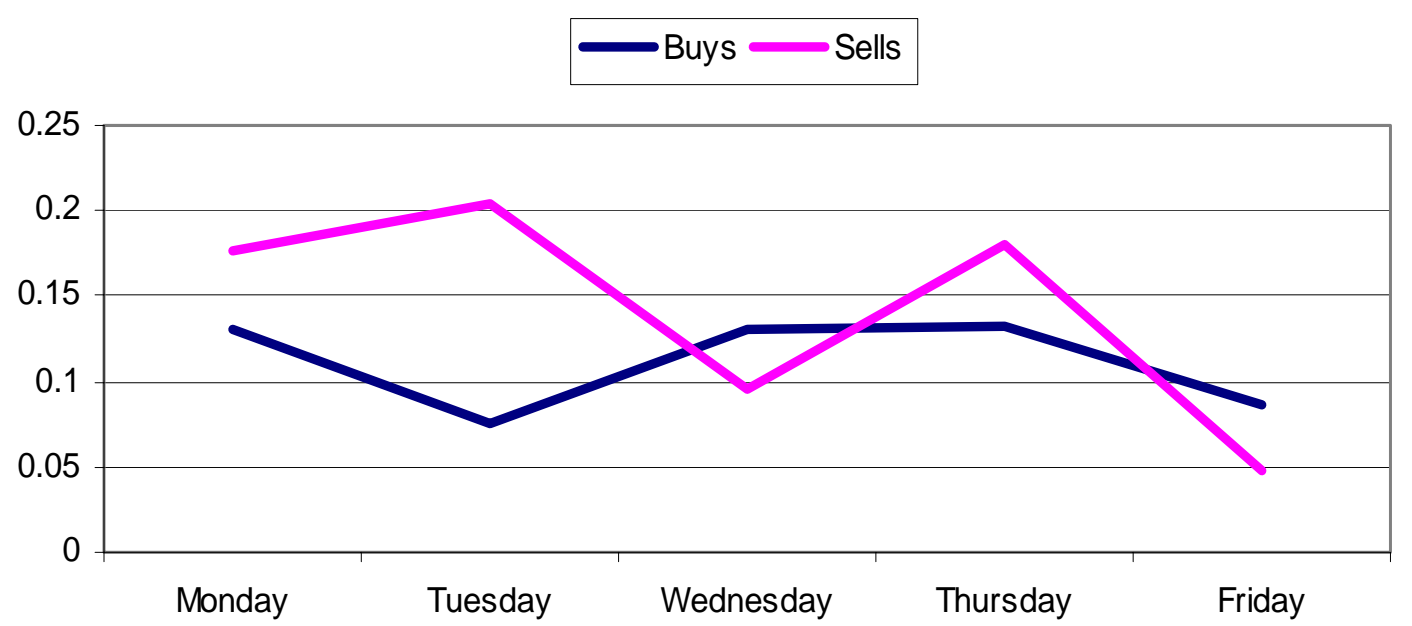

Figure 4. This plots average trading costs ( in percent) of U.S. stocks between 2001-2003. This represents average costs of 124,699 trades for 293 mutual funds where trades were matched with underlying price information. Trading costs for buys are estimated as the difference of execution price from the valueweighted average price, VWAP, of all trades during the day divided by VWAP. Trading costs for sales are estimated estimated as the difference of value-weighted average price and execution divided by VWAP. 


\section{Number of Trades By Month}

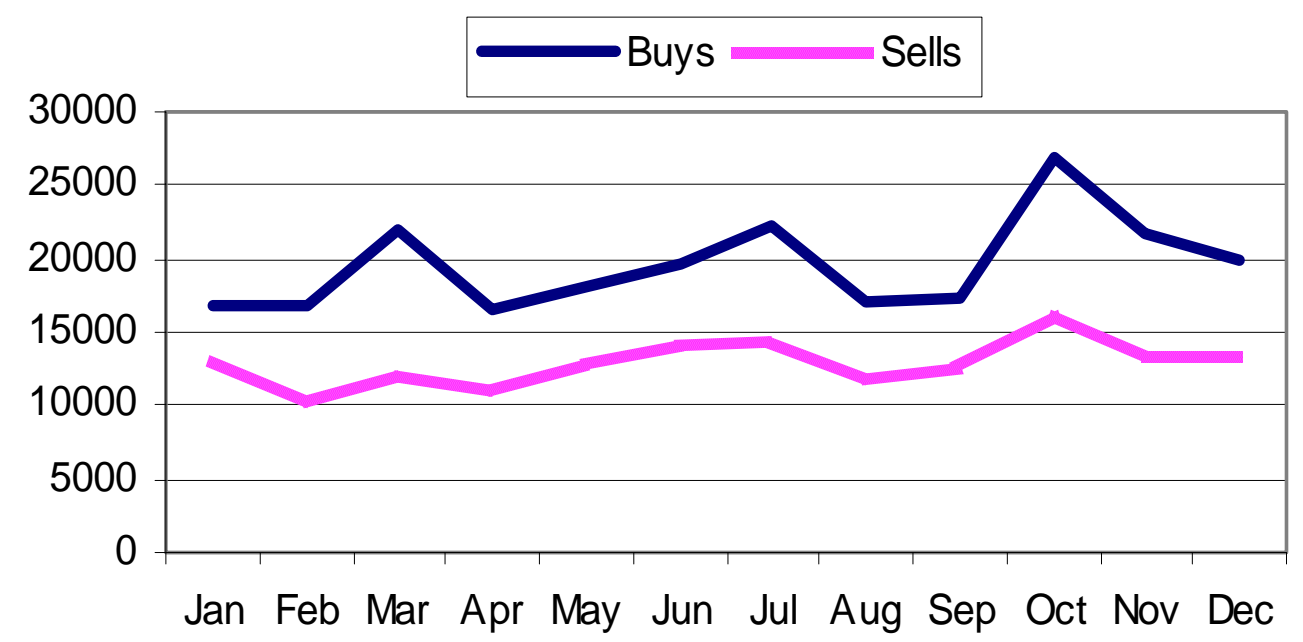

Figure 5. This plots the total number of trades in U.S. and Canadian for each month between 2001 to 2003. This represents all trades of 293 Canadian mutual funds. 


\section{Table I. Descriptive Statistics of Mutual Funds and Matched Sample}

Panel A of this table reports summary statistics for sample of 210 mutual funds in Canada. All data on mutual funds was collected from Morningstar Canada. This subsample of mutual funds cover 15\% of the Canadian mutual fund market. TNA is total net assets of the fund (aggregated across shareclasses) and TNASponsor is the total net assets of the sponsor of the fund. MER is the management expense ratio (in percent) for the fund. Net Monthly Returns are the monthly returns of the fund measured at the end of the month and deducting any expenses. All variables for the fund are available monthly and the averages are fund/month averages. Panel B shows how the data breaks down and the number of observations removed by matching and the removal of outliers.

\begin{tabular}{|c|c|c|c|c|c|c|}
\hline \multicolumn{7}{|c|}{ Panel A: Fund Characteristics across fund/months } \\
\hline & Obs & Average & Median & StDev & Min & Max \\
\hline TNA (\$millions) & 3116 & 300.95 & 94.72 & 595.65 & 0.038 & 6690.71 \\
\hline TNA Sponsor (\$billions) & 3216 & 18.24 & 6.91 & 20.23 & 0.0013 & 75.01 \\
\hline MER (Annual) & 2964 & 2.21 & 2.45 & 0.83 & 0 & 5.28 \\
\hline Net Monthly Returns (\%) & 3217 & 0.59 & 0.72 & 4.58 & -31.52 & 31.72 \\
\hline \multicolumn{7}{|c|}{ Panel B: Break-down of Data and Matching } \\
\hline & \multicolumn{2}{|c|}{ Unmatched Sample } & \multicolumn{2}{|c|}{ Matched CRSP } & \multicolumn{2}{|c|}{ Matched CRSP/MSTAR } \\
\hline Mutual Funds with Trades & \multicolumn{2}{|c|}{293} & \multicolumn{2}{|c|}{293} & \multicolumn{2}{|c|}{210} \\
\hline Total Trades in sample & \multicolumn{2}{|c|}{392269} & \multicolumn{2}{|c|}{230454} & \multicolumn{2}{|c|}{167100} \\
\hline Buys & \multicolumn{2}{|c|}{235633} & \multicolumn{2}{|c|}{141099} & \multicolumn{2}{|c|}{100015} \\
\hline Sells & \multicolumn{2}{|c|}{156636} & \multicolumn{2}{|c|}{89355} & \multicolumn{2}{|c|}{67085} \\
\hline Index Funds & \multicolumn{2}{|c|}{25} & \multicolumn{2}{|c|}{25} & \multicolumn{2}{|c|}{20} \\
\hline Portion of Trades in Canadian Stocks (\%) & \multicolumn{2}{|c|}{43.7} & \multicolumn{2}{|c|}{45.9} & \multicolumn{2}{|c|}{46.3} \\
\hline
\end{tabular}




\section{Table II. Descriptive Statistics of Trading Costs}

This table reports summary statistics for the trades in our sample of 210 mutual funds in Canada based on their interim and annual statements of portfolio transaction between January 2001 and June 2004. The execution price of a trade is estimated as the net dollar value of the trade divided by the number of shares traded. Trading costs for each trade are estimated as the difference between the execution price, P, and the value-weighted average price (VWAP) for all trades throughout the day divided by VWAP. For buys and sells, trading costs, TC, are defined in percent as

$$
T C_{\text {buy }}=\frac{(P-V W A P)}{V W A P} \text { and } T C_{\text {sell }}=\frac{(V W A P-P)}{V W A P} .
$$

Trade size is measured as both the dollar value of the trade divided by the market capitalization of the firm as well as the shares traded divided by the average trading volume in the preceding 20 days of the trade. The excess returns for one week ahead are the average compounded daily excess returns five trading days after the day of the trade. The log of daily excess returns are summed up across the five trading days and then divided by five. Each daily return is measured in logs and in excess of its respective market where the TSX300 index return is the market used for Canada and the S\&P500 is used for the U.S. Similar average daily excess returns are calculated for 1 month (21 trading days) after the trade. The value-weighted average weights the variable by the relative size of the trade measured by the dollar value of the trade as a percent of the total dollar value traded.

\begin{tabular}{|c|c|c|c|c|c|c|c|}
\hline \multicolumn{8}{|c|}{ Panel A: Buys of Canadian Stocks ( $\$ 17.65$ billion) } \\
\hline & Obs & Average & VWAvg & Median & StDev & Min & Max \\
\hline Trading Cost (\%) & 46131 & 0.1401 & 0.1464 & 0.1431 & 1.06 & -30.50 & 18.12 \\
\hline Number of Trades per month & 46131 & 118 & 96 & 81 & 112.16 & 1 & 540 \\
\hline Avg Size of Trade (\% Market Cap) & 46131 & 0.0192 & 0.0566 & 0.0040 & 0.05 & 2.07E-07 & 0.893 \\
\hline Avg Size of Trade ( $\%$ of Trading Volume) & 46131 & 6.3339 & 12.5113 & 1.3535 & 14.25 & $2.78 \mathrm{E}-05$ & 179.85 \\
\hline Avg Daily XS Returns 1 week ahead (\%) & 45993 & 0.0388 & 0.0312 & 0.0209 & 1.12 & -14.03 & 11.11 \\
\hline Avg Daily XS Returns 1 month ahead (\%) & 45910 & 0.0193 & 0.0225 & 0.0216 & 0.55 & -7.17 & 10.31 \\
\hline \multicolumn{8}{|c|}{ Panel B: Sells of Canadian Stocks ( $\$ 14.616$ billion) } \\
\hline & Obs & Average & VWAvg & Median & StDev & Min & Max \\
\hline Trading Cost $(\%)$ & 31235 & 0.1084 & 0.1048 & 0.1422 & 1.19 & -31.97 & 28.57 \\
\hline Number of Trades per month & 31235 & 84 & 87 & 64 & 71.68 & 1 & 353 \\
\hline Avg Size of Trade (\% Market Cap) & 31235 & 0.0250 & 0.0615 & 0.0056 & 0.06 & 9.47E-08 & 0.894 \\
\hline Avg Size of Trade ( $\%$ of Trading Volume) & 31235 & 7.3977 & 13.8632 & 1.6046 & 16.39 & $2.41 \mathrm{E}-05$ & 177.14 \\
\hline Avg Daily XS Returns 1 week ahead (\%) & 30673 & -0.0577 & -0.0477 & -0.0335 & 1.18 & -18.40 & 19.23 \\
\hline Avg Daily XS Returns 1 month ahead (\%) & 30647 & -0.0188 & -0.0326 & -0.0123 & 0.55 & -5.18 & 7.72 \\
\hline \multicolumn{8}{|c|}{ Panel C: Buys of US Stocks ( $\$ 11.736$ billion) } \\
\hline & Obs & Average & VWAvg & Median & StDev & Min & $\operatorname{Max}$ \\
\hline Trading Cost (\%) & 53884 & 0.1399 & 0.2333 & 0.1592 & 1.24 & -39.07 & 39.47 \\
\hline Number of Trades per month & 53884 & 182 & 121 & 98 & 240.24 & 1 & 1317 \\
\hline Avg Size of Trade (\% Market Cap) & 53884 & 0.0057 & 0.0234 & 0.0007 & 0.03 & $1.02 \mathrm{E}-08$ & 0.889 \\
\hline Avg Size of Trade ( $\%$ of Trading Volume) & 53884 & 0.9035 & 2.9870 & 0.0877 & 4.75 & $4.95 \mathrm{E}-06$ & 175.00 \\
\hline Avg Daily XS Returns 1 week ahead (\%) & 53879 & 0.0326 & -0.0182 & 0.0409 & 1.15 & -41.03 & 9.41 \\
\hline Avg Daily XS Returns 1 month ahead (\%) & 53837 & 0.0238 & -0.0024 & 0.0437 & 0.57 & -18.88 & 3.55 \\
\hline \multicolumn{8}{|c|}{ Panel D: Sells of US Stocks ( $\$ 9.95$ billion) } \\
\hline & Obs & Average & VWAvg & Median & StDev & Min & Max \\
\hline Trading Cost (\%) & 35850 & 0.1281 & 0.1737 & 0.1383 & 1.32 & -38.90 & 31.95 \\
\hline Number of Trades per month & 35850 & 121 & 72 & 73 & 163.26 & 1 & 895 \\
\hline Avg Size of Trade (\% Market Cap) & 35850 & 0.0070 & 0.0267 & 0.0010 & 0.03 & 7.09E-08 & 0.842 \\
\hline Avg Size of Trade ( $\%$ of Trading Volume) & 35850 & 1.0579 & 3.2896 & 0.1148 & 5.15 & $5.40 \mathrm{E}-06$ & 178.07 \\
\hline Avg Daily XS Returns 1 week ahead (\%) & 35829 & -0.0273 & 0.0099 & 0.0034 & 1.21 & -21.89 & 12.82 \\
\hline Avg Daily XS Returns 1 month ahead (\%) & 35780 & -0.0018 & -0.0340 & 0.0223 & 0.59 & -12.50 & 4.65 \\
\hline
\end{tabular}




\section{Table III. Trading Cost Regression}

This table estimates trading costs of buys and sells for 210 mutual funds in Canada based on their interim and annual statements of portfolio transaction between January 2001 and June 2004. The execution price of a trade is estimated as the net dollar value of the trade divided by the number of shares traded. Trading costs for each trade are estimated as the difference between the execution price, $\mathrm{P}$, and the value-weighted average price (VWAP) for all trades throughout the day divided by VWAP. For buys and sells, trading costs, TC, are defined in percent as

$$
T C_{\text {buy }}=\frac{(P-V W A P)}{V W A P} \text { and } T C_{\text {sell }}=\frac{(V W A P-P)}{V W A P} .
$$

CanUS is an indicator which takes the value 1 if the stock is traded in Canada and 0 if the stock is traded in the U.S. In the case of cross-traded securities, we assume the default market is Canada. Active takes the value 1 if a fund was actively managed and 0 if a fund was an index fund. ClosePastTrade takes the value 1 if a trade occurred within 5 trading days of another trade in the same stock at the same fund and 0 otherwise. LogMktCap is the log of a firm's market capitalization which is the closing price multiplied by the number of shares each day. Vol/Shrout is the average volume of shares trading in the market for the 20 days before the trade divided by the shares outstanding of the firm. \$Trade/MktCap is the dollar value of the trade divided by the market capitalization of the firm. $\log T N A$ is the log of the total net assets of the fund (aggregated across shareclasses) and LogTNASponsor is the log of the total net assets of the sponsor of the fund. Total net assets for both the sponsor and fund are reported for the month of the trade. Spread is the difference between the closing ask and bid price for the stock divided by the midpoint and is expressed as a percent. FlowPos takes the value 1 if the flow into the fund in the month of the trade is positive and 0 otherwise. Fund flow is the difference of total net asset, TNA, at the end of the month coinciding with the trade less the previous month's TNA adjusted for returns, $\mathrm{TNA}_{\mathrm{t}-1}\left(1+\mathrm{R}_{\mathrm{t}}\right)$ and divided by last month's TNA. Huber/White adjusted standard errors are reported to adjust for heteroskedasticity. The last two columns provide the difference in coefficients between sells and buys, CoefSells - CoefBuys. For the difference in coefficients on FlowPos, the reported difference is -CoefSells CoefBuys. Huber/White adjusted p-values are reported for each difference test.

\begin{tabular}{l|cc|cc|cc}
\hline & \multicolumn{2}{|c|}{ Buys } & \multicolumn{2}{c|}{ Sells } & \multicolumn{2}{c}{ Coefficient Difference } \\
& Coef & t-stat & Coef & t-stat & Sells - Buys & p-value \\
\hline CanUS & -0.0492 & -4.79 & -0.045594 & -3.52 & 0.0036 & 0.829 \\
Active & -0.1543 & -8.87 & -0.031585 & -1.70 & 0.1227 & 0.000 \\
ClosePastTrade & -0.0403 & -5.24 & -0.049371 & -4.93 & -0.0091 & 0.473 \\
LogMktCap & -0.0241 & -8.94 & -0.008327 & -1.96 & 0.0157 & 0.002 \\
Vol/Shrout & -1.4230 & -2.18 & -0.983876 & -1.30 & 0.4391 & 0.660 \\
Trade/MktCap & 112.6958 & 7.68 & 65.051824 & 4.05 & -47.6440 & 0.029 \\
LogTNA & -0.0164 & -7.53 & -0.020941 & -6.37 & -0.0046 & 0.248 \\
LogTNASponsor & 0.0057 & 1.97 & 0.007501 & 1.82 & 0.0018 & 0.726 \\
Spread & 0.0020 & 0.25 & 0.0172623 & 0.90 & 0.0152 & 0.465 \\
FlowPos & -0.0076 & -0.89 & -0.04215 & -3.81 & 0.0497 & 0.000 \\
Intercept & 0.8915 & 12.18 & 0.425452 & 3.72 & -0.4661 & 0.000 \\
Obs & \multicolumn{7}{c|}{6} & & & \\
R-squared & 94549 & & & & \\
\hline
\end{tabular}




\section{Table IV. Information in Trades Regression}

This table estimates future excess daily returns of buy and sell trades for 210 mutual funds in Canada based on their interim and annual statements of portfolio transaction from January 2001 and June 2004. The excess returns for one week ahead are the average compounded daily excess returns (in percent) five trading days after the day of the trade. The log of daily excess returns are summed up across the five trading days and then divided by five. Each daily return is measured in logs and in excess of its respective market where the TSX300 index return is the market used for Canada and the S\&P500 is used for the U.S. Similar average daily excess returns are calculated for 1 month (21 trading days) and 3 months (63 trading days) after the trade. CanUS is an indicator taking the value 1 if the stock is traded in Canada and 0 if the stock is traded in the U.S. In the case of cross-traded securities, we assume the default market is Canada. Active takes the value 1 if a fund was actively managed and 0 if a fund was an index fund. ClosePastTrade takes the value 1 if a trade occurred within 5 trading days of another trade in the same stock at the same fund and 0 otherwise. ClosePastTrade 2 takes the value 1 if a trade occurred within 5 trading days of another trade in the same stock at the same fund and there are no trades in the same stock for the same fund for 5 trading days after the trade. LogMktCap is the log of a firm's market capitalization which is the closing price multiplied by the number of shares each day.

Trade/MktCap is the dollar value of the trade divided by the market capitalization of the firm. LogTNA is the log of the total net assets of the fund (aggregated across shareclasses) and LogTNASponsor is the log of the total net assets of the sponsor of the fund. Total net assets for both the sponsor and fund are reported for the month of the trade. Spread is the difference between the closing ask and bid price for the stock divided by the midpoint. FlowPos takes the value 1 if the flow into the fund in the month of the trade is positive and 0 otherwise. Fund flow is the difference of total net asset, TNA, at the end of the month coinciding with the trade less the previous month's TNA adjusted for returns, TNA $_{t-}$ ${ }_{1}\left(1+\mathrm{R}_{\mathrm{t}}\right)$ and divided by last month's TNA. XSReturn Lagged 1 Month is the lagged compounded excess return in percent for the stock in the 21 trading preceding the trade (excluding the return on the trade day). T-statistics are reported in italics below each coefficient and use Huber/White adjusted standard errors adjust for heteroskedasticity. Panel A reports future returns for buy trades and Panel B reports future returns for sell trades.

Panel A: Future Returns of Buy Trades

\begin{tabular}{|c|c|c|c|c|c|c|}
\hline \multirow[b]{3}{*}{ CanUS } & \multicolumn{6}{|c|}{ Average Daily Excess Returns Looking Forward } \\
\hline & \multicolumn{2}{|c|}{1 week } & \multicolumn{2}{|c|}{1 month } & \multicolumn{2}{|c|}{3 month } \\
\hline & -0.010 & -0.011 & -0.018 & -0.019 & -0.025 & -0.026 \\
\hline & -1.197 & -1.244 & -4.335 & -4.380 & -10.493 & -10.609 \\
\hline \multirow[t]{2}{*}{ Active } & 0.129 & 0.134 & 0.065 & 0.066 & 0.032 & 0.031 \\
\hline & 9.130 & 9.532 & 8.944 & 9.026 & 7.424 & 7.298 \\
\hline \multirow[t]{2}{*}{ ClosePastTrade } & 0.019 & & 0.002 & & -0.003 & \\
\hline & 2.485 & & 0.506 & & -1.370 & \\
\hline \multirow[t]{2}{*}{ ClosePastTrade2 } & & 0.040 & & 0.008 & & 0.004 \\
\hline & & 3.964 & & 1.620 & & 1.422 \\
\hline \multirow[t]{2}{*}{ Log Mkt Cap } & -0.023 & -0.024 & -0.015 & -0.015 & -0.014 & -0.013 \\
\hline & -9.289 & -9.686 & -12.784 & -12.925 & -19.368 & -19.303 \\
\hline \multirow[t]{2}{*}{ Trade/MktCap } & -27.308 & -28.989 & -1.613 & -1.768 & -3.844 & -3.545 \\
\hline & -2.301 & -2.447 & -0.291 & -0.319 & -1.188 & -1.096 \\
\hline \multirow[t]{2}{*}{ LogTNA } & 0.009 & 0.010 & 0.002 & 0.002 & -0.003 & -0.003 \\
\hline & 4.204 & 4.577 & 2.240 & 2.344 & -4.915 & -5.011 \\
\hline \multirow[t]{2}{*}{ LogTNASponsor } & 0.009 & 0.009 & 0.005 & 0.005 & 0.002 & 0.002 \\
\hline & 3.474 & 3.517 & 3.990 & 3.998 & 3.125 & 3.090 \\
\hline \multirow[t]{2}{*}{ FlowPos } & 0.006 & 0.005 & -0.012 & -0.012 & -0.019 & -0.019 \\
\hline & 0.745 & 0.611 & -2.917 & -2.956 & -8.370 & -8.329 \\
\hline \multirow[t]{2}{*}{ XSReturn Lagged 1Month } & 0.013 & 0.014 & 0.183 & 0.183 & 0.121 & 0.121 \\
\hline & 0.274 & 0.305 & 6.549 & 6.558 & 8.925 & 8.901 \\
\hline \multirow[t]{2}{*}{ Intercept } & 0.297 & 0.311 & 0.253 & 0.254 & 0.295 & 0.292 \\
\hline & 4.602 & 4.841 & 8.050 & 8.127 & 16.701 & 16.613 \\
\hline Obs & 94016 & 94016 & 93916 & 93916 & 93672 & 93672 \\
\hline R-squared & 0.0026 & 0.0027 & 0.0056 & 0.0056 & 0.0101 & 0.0101 \\
\hline
\end{tabular}




\section{Table IV (Cont.) Information in Trades Regression}

This table estimates future excess daily returns of buy and sell trades for 210 mutual funds in Canada based on their interim and annual statements of portfolio transaction from January 2001 and June 2004. The excess returns for one week ahead are the average compounded daily excess returns (in percent) five trading days after the day of the trade. The log of daily excess returns are summed up across the five trading days and then divided by five. Each daily return is measured in logs and in excess of its respective market where the TSX300 index return is the market used for Canada and the S\&P500 is used for the U.S. Similar average daily excess returns are calculated for 1 month (21 trading days) and 3 months (63 trading days) after the trade. CanUS is an indicator taking the value 1 if the stock is traded in Canada and 0 if the stock is traded in the U.S. In the case of cross-traded securities, we assume the default market is Canada. Active takes the value 1 if a fund was actively managed and 0 if a fund was an index fund. ClosePastTrade takes the value 1 if a trade occurred within 7 days of another trade in the same stock at the same fund and 0 otherwise.

ClosePastTrade 2 takes the value 1 if a trade occurred within 7 days of another trade in the same stock at the same fund and there are no trades in the same stock for the same fund for 7 days after the trade. LogMktCap is the log of a firm's market capitalization which is the closing price multiplied by the number of shares each day. Trade/MktCap is the dollar value of the trade divided by the market capitalization of the firm. LogTNA is the log of the total net assets of the fund (aggregated across shareclasses) and LogTNASponsor is the log of the total net assets of the sponsor of the fund. Total net assets for both the sponsor and fund are reported for the month of the trade. Spread is the difference between the closing ask and bid price for the stock divided by the midpoint. FlowPos takes the value 1 if the flow into the fund in the month of the trade is positive and 0 otherwise. Fund flow is the difference of total net asset, TNA, at the end of the month coinciding with the trade less the previous month's TNA adjusted for returns, $\mathrm{TNA}_{\mathrm{t}-1}\left(1+\mathrm{R}_{\mathrm{t}}\right)$ and divided by last month's TNA. XSReturn Lagged 1 Month is the lagged compounded excess return (in percent) for the stock in the 21 trading preceding the trade (excluding the return on the trade day). T-statistics are reported in italics below each coefficient and are use Huber/White adjusted standard errors adjust for heteroskedasticity. Panel A reports future returns for buy trades and Panel B reports future returns for sell trades.

\begin{tabular}{|c|c|c|c|c|c|c|}
\hline \multicolumn{7}{|c|}{ Panel B: Future Returns of Sell Trades } \\
\hline & \multicolumn{6}{|c|}{ Average Daily Excess Returns Looking Forward } \\
\hline & \multicolumn{2}{|c|}{1 week } & \multicolumn{2}{|c|}{1 month } & \multicolumn{2}{|c|}{3 month } \\
\hline \multirow[t]{2}{*}{ CanUS } & -0.045 & -0.045 & -0.029 & -0.029 & -0.028 & -0.028 \\
\hline & -3.728 & -3.781 & -5.162 & -5.188 & -8.691 & -8.672 \\
\hline \multirow[t]{2}{*}{ Active } & -0.071 & -0.086 & -0.037 & -0.041 & 0.004 & 0.005 \\
\hline & -4.107 & -4.993 & -4.883 & -5.355 & 0.893 & 1.147 \\
\hline \multirow[t]{2}{*}{ ClosePastTrade } & -0.046 & & -0.008 & & 0.004 & \\
\hline & -4.763 & & -1.670 & & 1.354 & \\
\hline \multirow[t]{2}{*}{ ClosePastTrade2 } & & -0.015 & & 0.011 & & 0.003 \\
\hline & & -1.158 & & 1.716 & & 0.693 \\
\hline \multirow[t]{2}{*}{ Log Mkt Cap } & 0.007 & 0.009 & -0.006 & -0.005 & -0.012 & -0.013 \\
\hline & 1.882 & 2.407 & -3.219 & -3.103 & -12.558 & -12.851 \\
\hline \multirow[t]{2}{*}{ Trade/MktCap } & 68.098 & 72.534 & 31.368 & 32.070 & 8.073 & 7.723 \\
\hline & 3.857 & 4.105 & 4.048 & 4.140 & 2.018 & 1.936 \\
\hline \multirow[t]{2}{*}{ LogTNA } & -0.008 & -0.010 & -0.009 & -0.009 & -0.001 & -0.001 \\
\hline & -2.642 & -3.156 & -6.024 & -6.241 & -1.783 & -1.650 \\
\hline \multirow[t]{2}{*}{ LogTNASponsor } & -0.007 & -0.008 & -0.003 & -0.003 & 0.000 & 0.000 \\
\hline & -2.012 & -2.096 & -1.869 & -1.854 & -0.156 & -0.124 \\
\hline \multirow[t]{2}{*}{ FlowPos } & 0.006 & 0.002 & -0.018 & -0.019 & -0.026 & -0.026 \\
\hline & 0.563 & 0.194 & -3.674 & -3.847 & -9.204 & -9.131 \\
\hline \multirow[t]{2}{*}{ XSReturn Lagged 1Month } & -0.095 & -0.087 & 0.045 & 0.045 & 0.039 & 0.038 \\
\hline & -1.345 & -1.239 & 1.232 & 1.247 & 2.279 & 2.242 \\
\hline \multirow[t]{2}{*}{ Intercept } & 0.004 & -0.037 & 0.243 & 0.236 & 0.307 & 0.310 \\
\hline & 0.037 & -0.379 & 5.405 & 5.277 & 12.137 & 12.340 \\
\hline Obs & 62705 & 62705 & 62646 & 62646 & 62414 & 62414 \\
\hline R-squared & 0.0018 & 0.0015 & 0.0028 & 0.0028 & 0.0070 & 0.0070 \\
\hline
\end{tabular}




\section{Table V. Trading Costs and Information for Buy Trades}

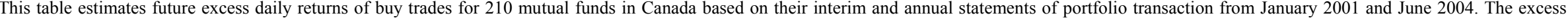

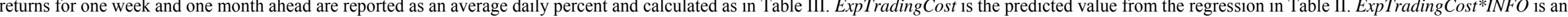

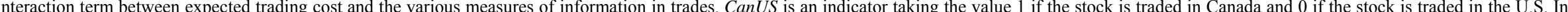

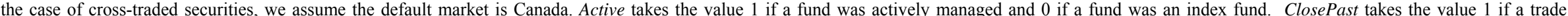

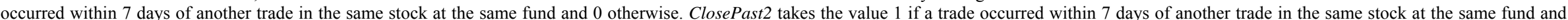

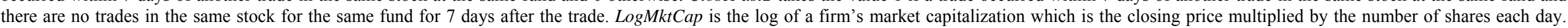

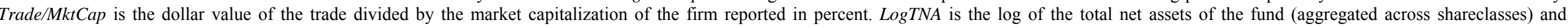

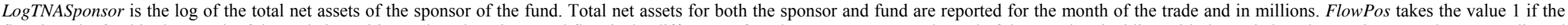

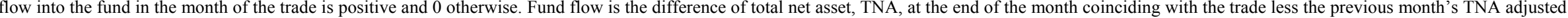

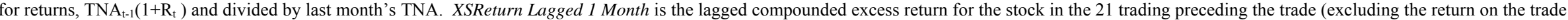
day) and reported in percent. T-statistics are reported in italics below each coefficient and are use Huber/White adjusted standard errors adjust for heteroskedasticity.

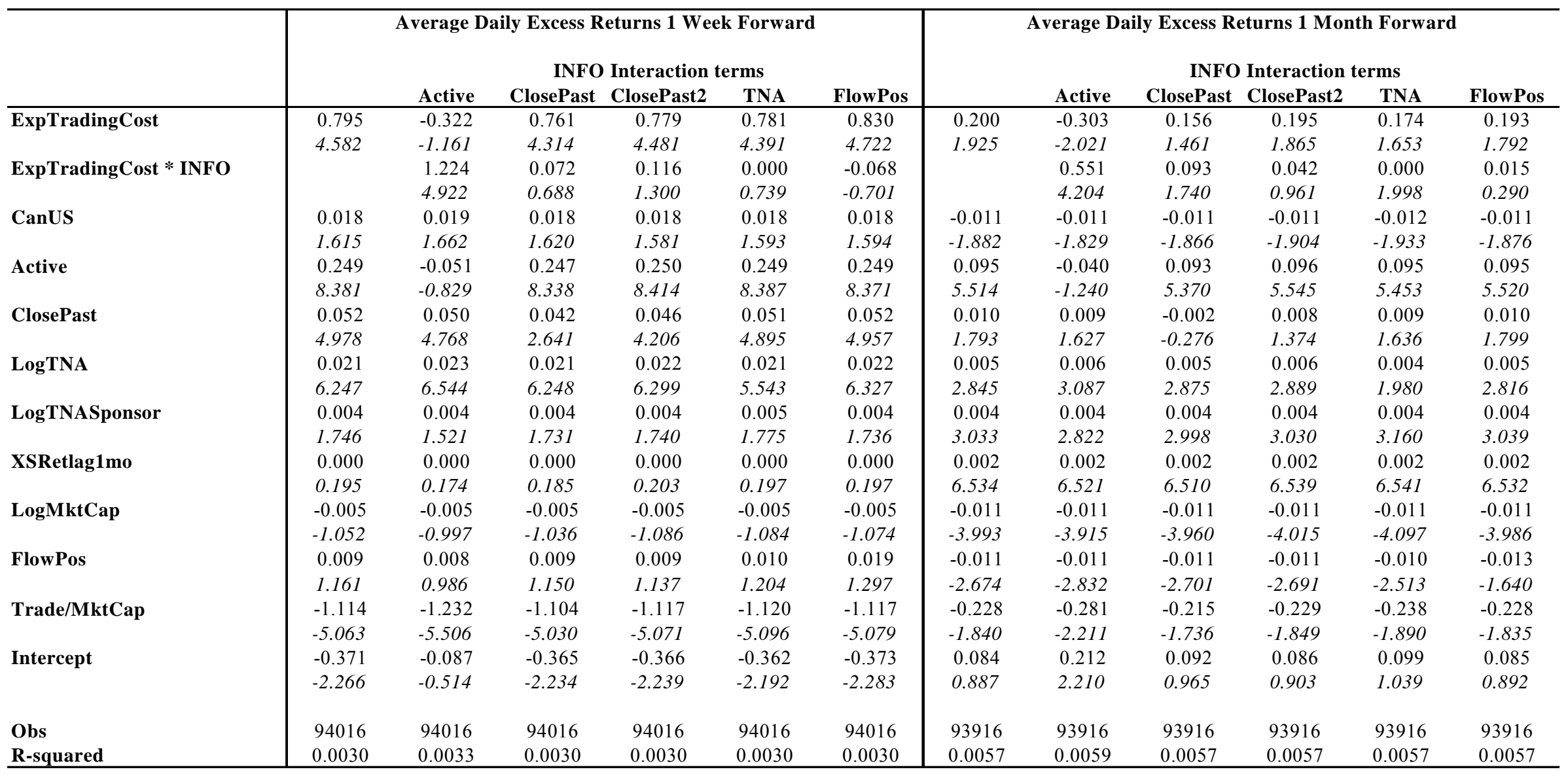


Table VI. Trading Costs and Information for Sell Trades

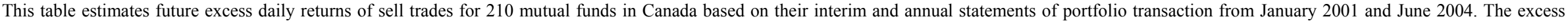

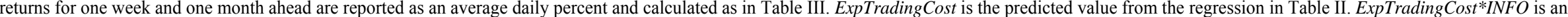

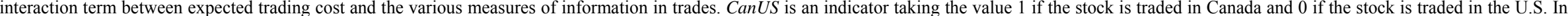

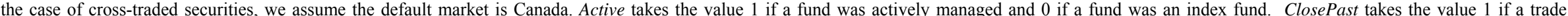

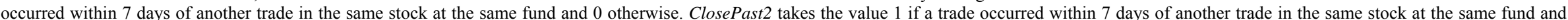

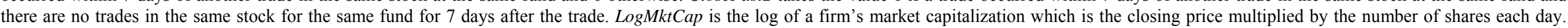

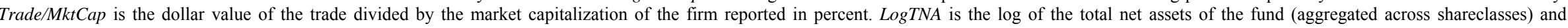

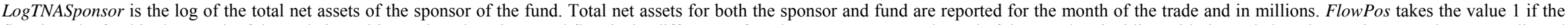

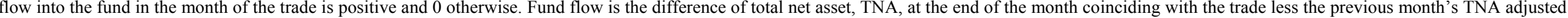

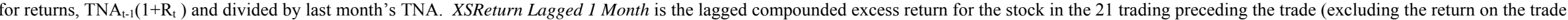
day) and reported in percent. T-statistics are reported in italics below each coefficient and are use Huber/White adjusted standard errors adjust for heteroskedasticity.

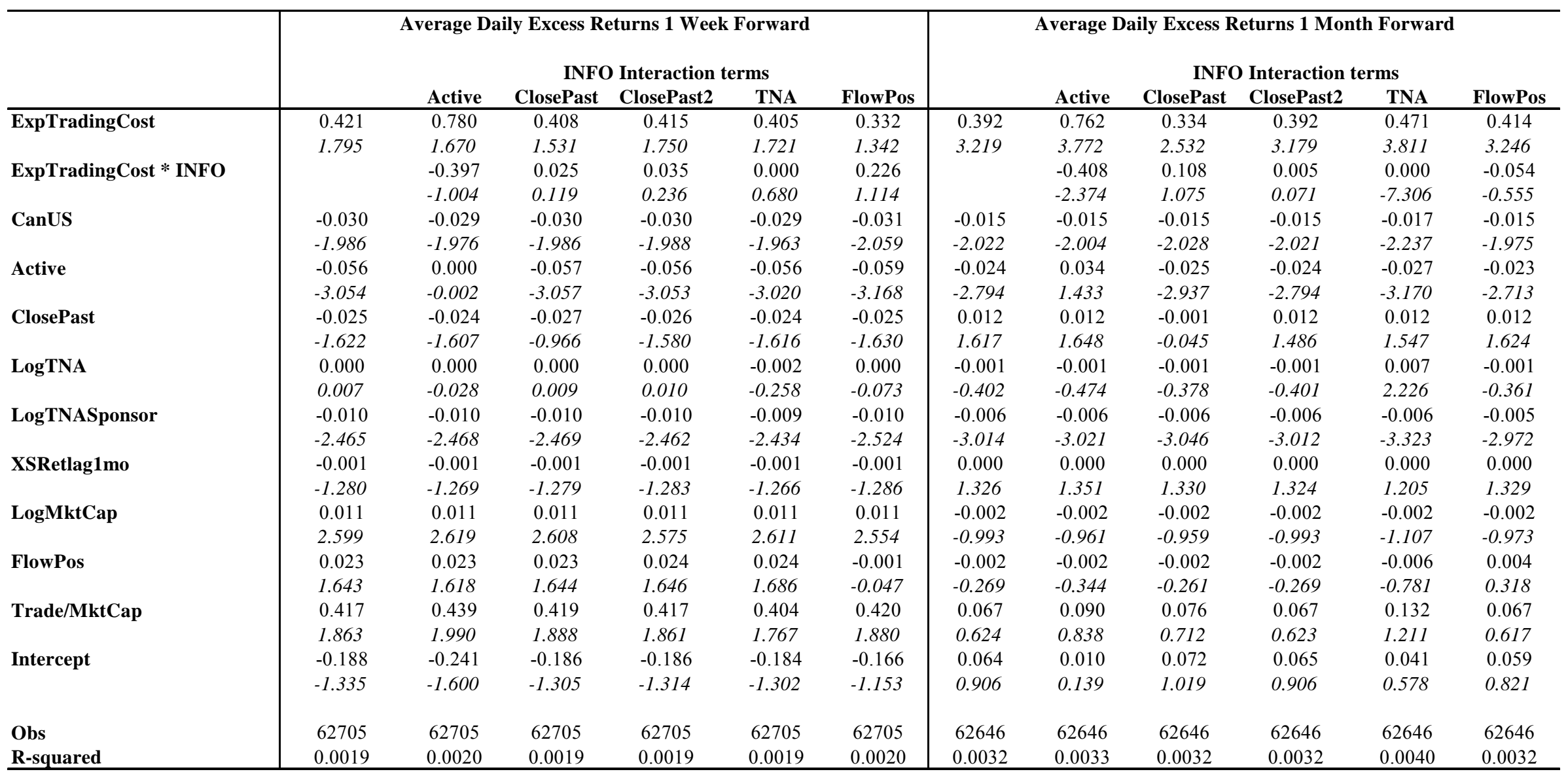

